OPEN ACCESS

Edited by:

Sophie Zuber

Nestlé Research Center, Switzerland

Reviewed by:

Matthew D. Moore,

University of Massachusetts Amherst

United States

Dan Li,

National University of Singapore,

Singapore

${ }^{*}$ Correspondence:

Ji-Hyoung $\mathrm{Ha}$

hajee@wikim.re.kr

tThese authors have contributed equally to this work

Specialty section: This article was submitted to

Food Microbiology,

a section of the journal

Frontiers in Microbiology

Received: 11 October 2020 Accepted: 27 May 2021

Published: 06 July 2021

Citation:

Kang $\mathrm{M}$, Park $\mathrm{B}$ and $\mathrm{Ha} \mathrm{J}-\mathrm{H}$ (2021) Kinetic Modeling of Slightly Acidic Electrolyzed Water Decay Characteristics in Fresh Cabbage Disinfection Against Human

Norovirus.

Front. Microbiol. 12:616297. doi: 10.3389/fmicb.2021.616297

\section{Kinetic Modeling of Slightly Acidic Electrolyzed Water Decay Characteristics in Fresh Cabbage Disinfection Against Human Norovirus}

\author{
Miran Kangt, Boyeon Park ${ }^{\dagger}$ and Ji-Hyoung Ha* \\ Hygienic Safety and Analysis Center, World Institute of Kimchi, Gwangju, South Korea
}

To consistently disinfect fresh vegetables efficiently, the decay of disinfectants such as chlorine, electrolyzed oxidizing water (EOW), ozonated water, and plasma-activated water during the disinfection maintenance stage needs to be understood. The aim of our study was to evaluate the changes in the inactivation kinetics of slightly acidic electrolyzed water (SAEW) against human norovirus (HuNoV), based on the cabbageto-SAEW ratio. After disinfection of fresh cabbage with disinfected SAEW solution, SAEW samples were collected and analyzed for physicochemical properties such as $\mathrm{pH}$, available chlorine concentrations (ACCs), and oxidation-reduction potential (ORP). SAEW virucidal effects were evaluated. We confirmed the decay of post-disinfection SAEW solution and demonstrated the different patterns of the decay kinetic model for HuNoV Gl.6 and Gll.4. In addition, the goodness of fit of the tested models based on a lower Akaike information criterion, root-mean-square error (RMSE), and residual sum of squares (RSS) was close to zero. In particular, the change in both the HuNoV GI.6 and Gll.4 inactivation exhibited a strong correlation with the changes in the ACC of post-disinfection SAEW. These findings demonstrate that physicochemical parameters of SAEW play a key role in influencing the kinetic behavior of changes in the disinfection efficiency of SAEW during the disinfection process. Therefore, to optimize the efficiency of SAEW, it is necessary to optimize the produce-to-SAEW ratio in future studies.

Keywords: cabbage, disinfection, kinetic model, norovirus, SAEW decay

\section{INTRODUCTION}

The food industry has recognized the importance of hygiene practices and has established optimized processes to ensure food safety. For cleaning and sterilization processes, chemical compounds such as organic disinfectants like ethanol, chlorine compounds, iodine, quaternary ammonium compounds, and hydrogen peroxide have been utilized in various food processes (Hricova et al., 2008). Among chemical disinfection processes, chlorination is the most efficient; however, it can lead to the generation of potentially toxic halogenated disinfection by-products (DBPs) and corrode metal (Issa-Zacharia et al., 2011). The use of some chlorination treatments has been restricted due to discoloration or unpleasant odor of food products. Therefore, alternative 
disinfectants such as electrolyzed oxidizing water (EOW), ozonated water, and plasma-activated water have been evaluated for food safety and quality (Schwarz et al., 2019).

Slightly acidic electrolyzed water (SAEW) can be generated by electrolysis of sodium chloride or hydrochloric acid using a non-membrane electrolytic cell (Li et al., 2013). Recently, SAEW treatment with low available chlorine concentrations (ACCs), usually approximately $30 \mathrm{mg} / \mathrm{L}$ (the acceptable range is between 10 and $80 \mathrm{mg} / \mathrm{L}$ ), and a $\mathrm{pH}$ value between 5.0 and 6.0 , has been gaining attention as a disinfectant in the food industry to remove pathogenic bacterial populations on food-contact surfaces or food products (Suzuki et al., 2005). In various studies, the antibacterial effects of SAEW on foodborne pathogenic bacteria, such as Staphylococcus aureus, Salmonella enteritidis, and Escherichia coli, have been evaluated (Fenner et al., 2006; Ren and Su, 2006; Hao et al., 2014; Cap et al., 2019). The virucidal effects of electrolyzed water (EW) were investigated in human norovirus (HuNoV) GII.4 Sydney and cultivable $\mathrm{HuNoV}$ surrogates, for example, and murine norovirus in suspension and on stainless steel surfaces has also been evaluated (Park et al., 2007; Moorman et al., 2017). Moreover, SAEW and sodium hypochlorite treatment have an equivalent disinfection efficacy in fresh-cut cilantro, spinach, and cut cabbage samples (Koide et al., 2009; Rahman et al., 2010; Hao et al., 2011). Furthermore, Rahman et al. (2013) and Wang et al. (2014) demonstrated that SAEW treatment can be utilized to disinfect fresh shrimp and pork. Based on these experimental results, the United States Environmental Protection Agency (EPA) has approved the use of EW generators for disinfection in the food processing field. Moreover, the Japanese Ministry of Health, Labor and Welfare has also authorized EW as a food additive to reduce pathogenic microbial populations in various foods, food contact surfaces, and food processing surfaces.

Between pH 5.0 and 6.5, the most common active form of chlorine compounds among hypochlorite ions $\left(\mathrm{ClO}^{-}\right)$, chlorine gas $\left(\mathrm{Cl}_{2}\right)$, and hypochlorous acid $(\mathrm{HOCl})$ is $\mathrm{HOCl}(95 \%)$, which induces pathogenic microbial inactivation. The relative amounts of the $\mathrm{HOCl}, \mathrm{Cl}_{2}$, and $\mathrm{ClO}^{-}$species formed in SAEW solutions is $\mathrm{pH}$ dependent; therefore, changes in $\mathrm{pH}$ have a significant effect on the formation of chlorine compounds. Previous studies demonstrated that the SAEW is most effective in eliminating pathogenic microorganisms at a $\mathrm{pH}$ of approximately 5.5, when the proportion of $\mathrm{HOCl}$ is the highest (Hricova et al., 2008). Moreover, a specific oxidation-reduction potential (ORP), which indicates the ability to oxidize or reduce, has been reported to be the main factor influencing the antimicrobial activity of SAEW (Al-Haq et al., 2005). Thus, the antimicrobial effect of SAEW is influenced by specific factors such as $\mathrm{pH}, \mathrm{ACC}$, and ORP (Fabrizio and Cutter, 2004).

Maintaining SAEW treatment efficacy should be considered in disinfection processes for fruits or vegetables from the perspective of the relationship between disinfection parameters. The changes in the physicochemical properties of SAEW play an important role in ensuring the antimicrobial activity during the disinfection process. In disinfectant processes, previous studies pay more attention to the inactivation efficacy for pathogens; however, the decay of SAEW in the disinfection maintenance stage was not considered important. Recently, with the increase of the use of SAEW in washing and sanitization of fruits and vegetables, the decay behavior of SAEW in solution is gradually gaining attention. Therefore, understanding the properties of SAEW decay as cleaning agent and disinfectant could help to optimize SAEW disinfection treatment and help maintain disinfection efficiency in the food industry.

The objectives of our study were to investigate the changes in virucidal effects based on the operating variables of SAEW treatment in fresh cabbage. In this study, we investigated how much the deterioration of post-disinfection SAEW affects its ability to disinfect against $\mathrm{HuNoV}$. Moreover, we evaluated kinetic models to predict the changes in the physicochemical properties of SAEW and the deterioration of virucidal effects on HuNoVs. Finally, we determined the effect of cabbage-to-SAEW ratio as an operating variable on the disinfection of fresh cabbage by post-disinfection SAEW.

\section{MATERIALS AND METHODS}

\section{Virus Stocks}

HuNoV genogroup I genotype 6 (HuNoV GI.6) and genogroup II genotype 4 (HuNoV GII.4) were provided by Norogene (Seoul, South Korea). The HuNoV GI.6 and GII.4 stock samples were diluted in nuclease-free water (Ambion Inc., Austin, TX, United States) and vortexed briefly. The solution was stored in $500-\mu \mathrm{l}$ aliquots at $-80^{\circ} \mathrm{C}$.

\section{Preparation and Characterization of SAEW}

The SAEW was prepared from electrolysis of $7 \%$ hydrochloric acid, using a SAEW generator (Purester m-Clean; Morinaga Milk Industry Co., Ltd., Tokyo, Japan) at $12.8 \mathrm{~V}$ and 5.0 A. A dualscale $\mathrm{pH} / \mathrm{mV}$ meter (Accumet AB15; Fisher Scientific, Fair Lawn, NJ, United States) equipped with bearing ORP and $\mathrm{pH}$ electrodes was used to determine the ORP and $\mathrm{pH}$ values of the prepared solution. The ACC was measured using a colorimetric method of a digital chlorine test kit (RC-3F; Kasahara Chemical Co., Saitama, Japan). The SAEW generation rates were achieved at a flow rate of $10.0 \mathrm{~L} / \mathrm{min}$. Initial SAEW had an ORP of $975 \pm 2$ $\mathrm{mV}$, a pH range of $5.46 \pm 0.01$, and an ACC of $26.65 \pm 0.84 \mathrm{ppm}$. After production, the SAEW was placed in a stainless-steel tank developed in the lab for disinfection. The laboratory scale of SAEW tank is $1.6 \mathrm{~m}$ (length), $0.8 \mathrm{~m}$ (depth), and $0.8 \mathrm{~m}$ (width).

\section{Virucidal Effect of the Post-disinfection SAEW}

A schematic diagram of SAEW sampling for the $\mathrm{HuNoV}$ virucidal test in the experimental study is shown in Figure $\mathbf{1}$. For testing the virucidal effects of post-disinfection SAEW, 100 L of SAEW (fixed volume) and 50 samples of fresh cabbage (Brassica rapa L. subsp. pekinensis) were prepared. The cabbages were purchased from a supermarket in Gwangju, South Korea, and pre-sorted at $5^{\circ} \mathrm{C}$ and bruised outer leaves were removed and discarded. Each cabbage sample was weighed and recorded 
to calculate the ratio of cabbage (weight) to SAEW (volume). SAEW was collected for the virucidal test immediately after the weighed cabbage was sequentially washed in SAEW. Samples of post-disinfection SAEW solutions were collected and denoted by the ratio [fresh cabbage $(\mathrm{kg}) / 100 \mathrm{~L}$ of SAEW] of disinfecting trial at $0.025(2.54 \mathrm{~kg}), 0.113(11.27 \mathrm{~kg}), 0.234(23.42 \mathrm{~kg}), 0.356$ $(35.59 \mathrm{~kg}), 0.490(49.01 \mathrm{~kg}), 0.630(62.95 \mathrm{~kg}), 0.755(75.48 \mathrm{~kg})$, $0.884(88.42 \mathrm{~kg}), 0.997$ (99.65 kg), 1.136 (113.60 kg), and 1.266 $(126.63 \mathrm{~kg})$ disinfecting order, and assayed for virucidal effect. All experiments were performed twice. A modified DilutionNeutralization Method (European CEN EN 1,276 method) was used to evaluate the viral disinfection efficacy of post-disinfection SAEW. A quantitative suspension test of viral disinfection was performed as previously described by Ha et al. (2016). Briefly, $0.1 \mathrm{ml}$ of stock suspension of $\mathrm{HuNoV}$ (containing approximately $1.0 \mathrm{E}+5$ to $2.2 \mathrm{E}+5$ genomic RNA copies) was added into $0.9 \mathrm{ml}$ of each post-disinfection SAEW solution, based on the designated ratio. Phosphate buffered saline (PBS, $\mathrm{pH}$ 7.4, Sigma-Aldrich) was used as a negative control, and $2 \%$ sodium hypochlorite adjusted to $\mathrm{pH} 7.0$ (Sigma Aldrich) was used as a positive control. Then, they were quickly vortexed and incubated for $60 \mathrm{~s}$ at $20 \pm 2^{\circ} \mathrm{C}$, as suggested in the CEN EN 1276 protocol. Immediately following the SAEW contact time, $10 \mathrm{ml}$ of PBS was added to the mixture to neutralize the disinfection reaction.

\section{Quantification of HuNoV in Suspension Test}

HuNoV GI.6 and GII.4 concentration, elution, and quantification from SAEW disinfected sample groups were conducted as previously described by Lee et al. (2018). The following optimum method for quantification of HuNoV RNA particles from SAEW-disinfected samples was used: an anionic polymercoated magnetic bead separation (MBS)/reverse transcription quantitative polymerase chain reaction (RT-qPCR) method with pretreatment combining sodium lauroyl sarcosinate (INCI) and propidium monoazide (PMA) (denoted as MBS/INCI/PMA/RTqPCR assay). Lee et al. (2018) used $200 \mu \mathrm{M}$ PMA to quantify HuNoV GI.6 and GII.4 viral RNA. The optimum concentration of $0.5 \%$ INCI, which caused minimal damage to intact HuNoVs viral particles, was used. HuNoV RNA was precipitated by mixing the viral solution with $97 \%$ ethanol and mixed with AVL extraction buffer and carrier RNA. A QIAamp spin column (Qiagen, Hilden, Germany) was used to purify the viral RNA sample. After two wash steps with AW1 and AW2 buffers, $60 \mu \mathrm{l}$ of elution buffer (AVE) was used to elute the viral RNA. A 5- $\mu$ l aliquot of each test sample was placed in a PCR tube directly for RT-qPCR. HuNoV viral particles were recovered using commercial Viro-adembeads (Ademtech, Pessac, France) after disinfection tests. The beads were prepared by coating with poly(methyl vinyl ether-maleic anhydride), and virus capture was conducted according to the manufacturer's procedure. A $5 \mathrm{mg} / \mathrm{ml}$ (final concentration) of nanosized magnetic bead mixture was added to the disinfected $\mathrm{HuNoV}$ viral suspension and shaken for $1 \mathrm{~h}$ at $20 \pm 2{ }^{\circ} \mathrm{C}$ to combine the viral particles. The bead mixture with combined $\mathrm{HuNoV}$ viral particles was recovered using the PolyATtract System 1000 (Promega, Madison, WI, United States) and resuspended in 100 $\mu l$ of PBS.

\section{Viral RNA Extraction and RT-qPCR}

Viral RNA was eluted with $60 \mu \mathrm{l}$ of AVE buffer using a QIAamp MinElute virus spin kit (Qiagen, Hilden, Germany) and then purified RNA was used immediately to avoid template RNA freezing. A 5- $\mu$ l aliquot of each RNA test sample was used directly in a one-step RT-qPCR (7500 Fast Real Time PCR System, Applied Biosystems, Foster City, CA, United States) using the QuantiTect Probe RT-PCR kit (Qiagen). For HuNoV GI.6 and GII4, RTqPCR was performed using $5 \mu \mathrm{l}$ of RNA elute in a total volume of $20 \mu \mathrm{l}$ with the following cycling parameters: $50^{\circ} \mathrm{C}$ for $600 \mathrm{~s}$, denaturation at $95^{\circ} \mathrm{C}$ for $300 \mathrm{~s}$, and 40 cycles of amplification with denaturation at $95^{\circ} \mathrm{C}$ for $10 \mathrm{~s}$ and combined annealing and extension at $60^{\circ} \mathrm{C}$ for $30 \mathrm{~s}$. NoV GI primer (10 pmol each) sequences were $5^{\prime}$-JJV1R TCCTTAGACGCCATCATCAT-3' (reverse) and JJV1F 5'GCCATGTTCCGITGGATG-3' (forward), which were used to amplify the 96-base pair (bp) fragment of the NoV GI polymerase gene. The TaqMan probe (JJV1P) sequence was FAM 5'-TGTGGACAGGAGATCGCAATCTC-3' BHQ (Gentry et al., 2009). The NoV GII.4 primer sequences (10 mM each) were COG2R: 5'-TCGACGCCATCTTCATTCACA-3' and COG2F: 5'-CARGARBCNATGTTYAGRTGGATG AG-3', which amplified a 122-bp fragment of the NoV GII.4 (Lee et al., 2018). The TaqMan probe (Ring2, $10 \mathrm{mM}$ ) was FAM: 5'-TGGGAGGGCGATCGCAATCT-3' BHQ. All amplifications were performed in triplicate.

\section{Quantification of NoV RNA}

To plot external standard curves of HuNoV GI.6 and GII.4, quantitative synthetic norovirus G1 (I) RNA (ATCC ${ }^{\circledR}$ VR3234SD ${ }^{\mathrm{TM}}$, ATCC, Manassas, VA, United States) and G2 (II) RNA (ATCC ${ }^{\circledR}$ VR3235SD ${ }^{\mathrm{TM}}$ ) containing the ORF1- and ORF2junction region was sequentially diluted 10 -fold from 2.0 to 6.0 $\log _{10}$ genomic RNA copy numbers. The standard RNA curves of both NoV GI.6 and GII.4 had slopes of $-3.264\left(R^{2}=0.9953\right)$ and $-3.371\left(R^{2}=0.9981\right)$, respectively. The initial titers of NoV GI.6 and GII.4 were approximately 5.31 and $5.08 \log _{10}$ genomic copies per RT-qPCR reaction, respectively.

\section{Data Analyses of the Decay Kinetic Model}

Reduction values of $\mathrm{HuNoV}$ viral titer in $\log 10$ was calculated as cabbage washing accumulated over all trials, and two mathematical decay kinetic models were fitted to the average $\mathrm{HuNoV}$ viral titer using the SigmaPlot software (version 14.0, San Jose, CA, United States) with the decay kinetic models (Eq. 1). This equation is expressed below:

$$
\begin{aligned}
& \text { Reduction values of } \mathrm{HuNoV}= \\
& \qquad a \times \exp (\mathrm{b} \times(\text { cabbage loading ratio })),
\end{aligned}
$$




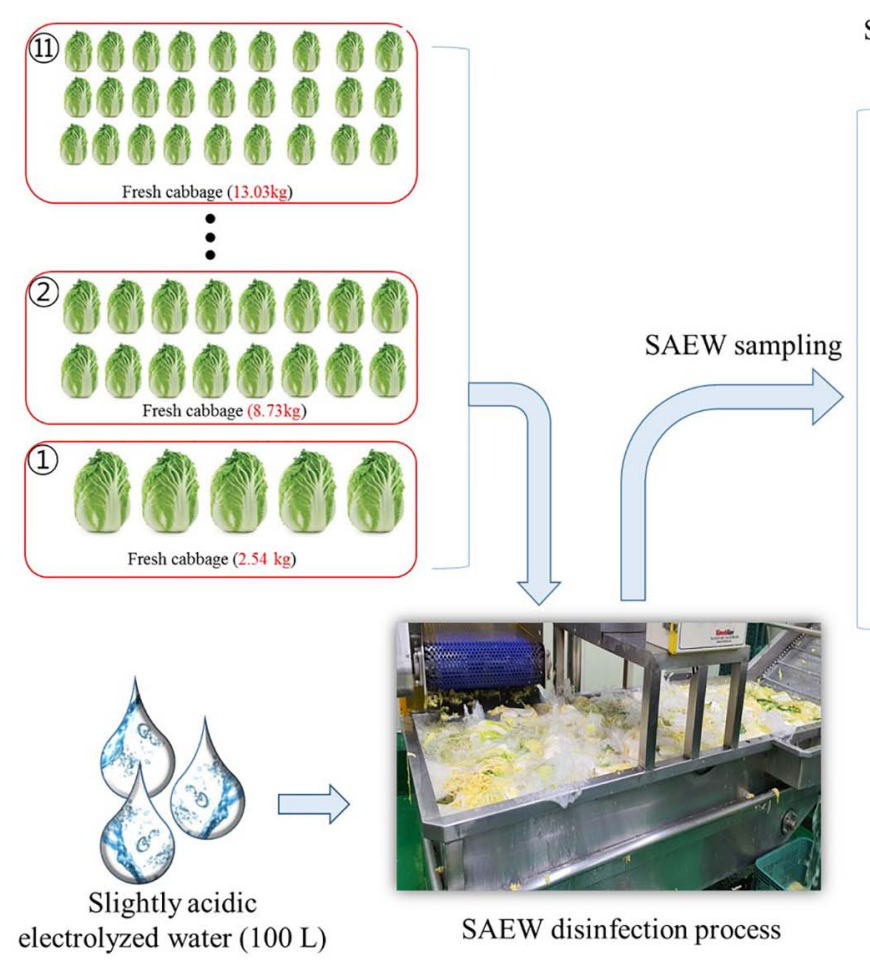

Sampling order point by the cabbage loading ratio (fresh cabbage $(\mathrm{kg}) / 100 \mathrm{~L}$ of SAEW)
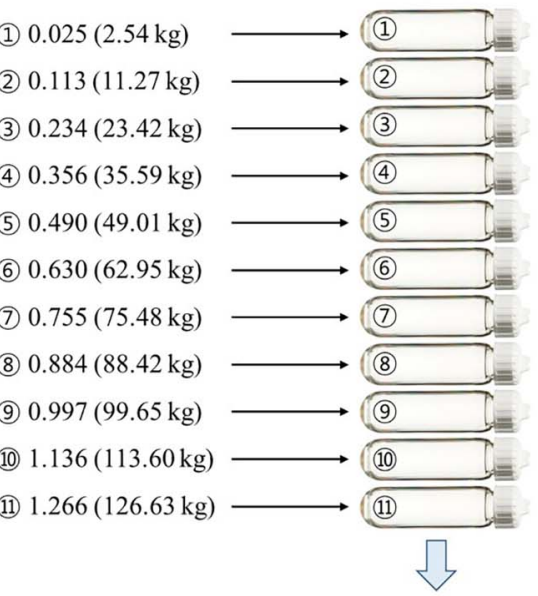

Physiochemical analysis Virucidal effect test of collected SAEW of collected SAEW

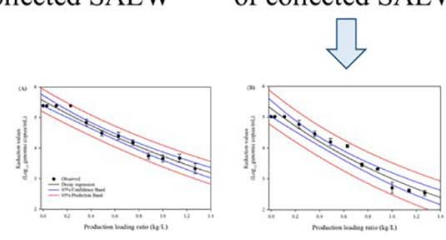

Data analyses of the decay kinetic model

FIGURE 1 | Schematic diagram of the SAEW sampling for virucidal test of HuNoV.

where $a$ and $b$ are regression parameters. For the sum of squares optimization, the Akaike information criterion (AIC) formula (Eq. 2) was used as expressed below:

$$
A I C=n \times \ln \left(\frac{s s}{n}\right) \times 2 \times k
$$

where $n$ is the number of observations, $k$ is the number of estimated parameters in the model, and $s s$ is the sum of squares. The root-mean-square error (RMSE) of the mathematical kinetic model prediction with respect to the estimated variable $Y_{\text {model }}$ is defined as the square root of the mean squared error (Eq. 3):

$$
\mathrm{RMSE}=\sqrt{\frac{\sum \frac{n}{i=1}\left(Y_{o b s, i}-Y_{\text {model }, i}\right)^{2}}{n-k}}
$$

where $n$ is the number of observations, $k$ is the number of estimated parameters in the model, $Y_{\text {obs }}$ is the observed value, and $Y_{\text {model }}$ is the modeled value at cabbage loading ratio $i$. The residual sum of squares (RSS) is the sum of the squared distances between predicted values versus actual treated data:

$$
\mathrm{RSS}=\sum_{i=1}^{n}\left(Y_{o b s, i}-Y_{m o d e l, i}\right)^{2}
$$

where $Y_{\text {obs }}$ is the observed value and $Y_{\text {model }}$ is the modeled value at cabbage loading ratio $i$.

\section{Statistical Analysis}

Duplicate samples were used in each operating variable (cabbageto-SAEW ratio), and the experiments were repeated in triplicate. For statistical analysis, one-way ANOVA and Duncan's multiple range test were used to compare differences among mean values using SPSS Statistics (software v.8.2, Inc., Chicago, IL, United States). $P$-value $<0.05$ was defined as significant. The experimental results are denoted as $\log _{10}$ genomic copies/ $\mu l$, and regression analysis was performed using the SigmaPlot software system (ver. 14.0).

\section{RESULTS}

\section{Changes in the Physicochemical Properties of SAEW}

We investigated whether the ratio of fresh cabbage loaded to the fixed volume of SAEW affected the physicochemical characteristics of SAEW. After disinfection and washing, the SAEW solution was sampled according to the specified product loading ratio (kilogram of fresh cabbage per liter of SAEW; $\mathrm{kg} / \mathrm{L}$ ). The changes in $\mathrm{pH}, \mathrm{ORP}$, and ACC of SAEW sampled after disinfection and washing fresh cabbages are shown in Figure 2. As the product loading ratio increased, the $\mathrm{pH}$ value decreased significantly. When the cabbage/SAEW ratio was 0.3 , 


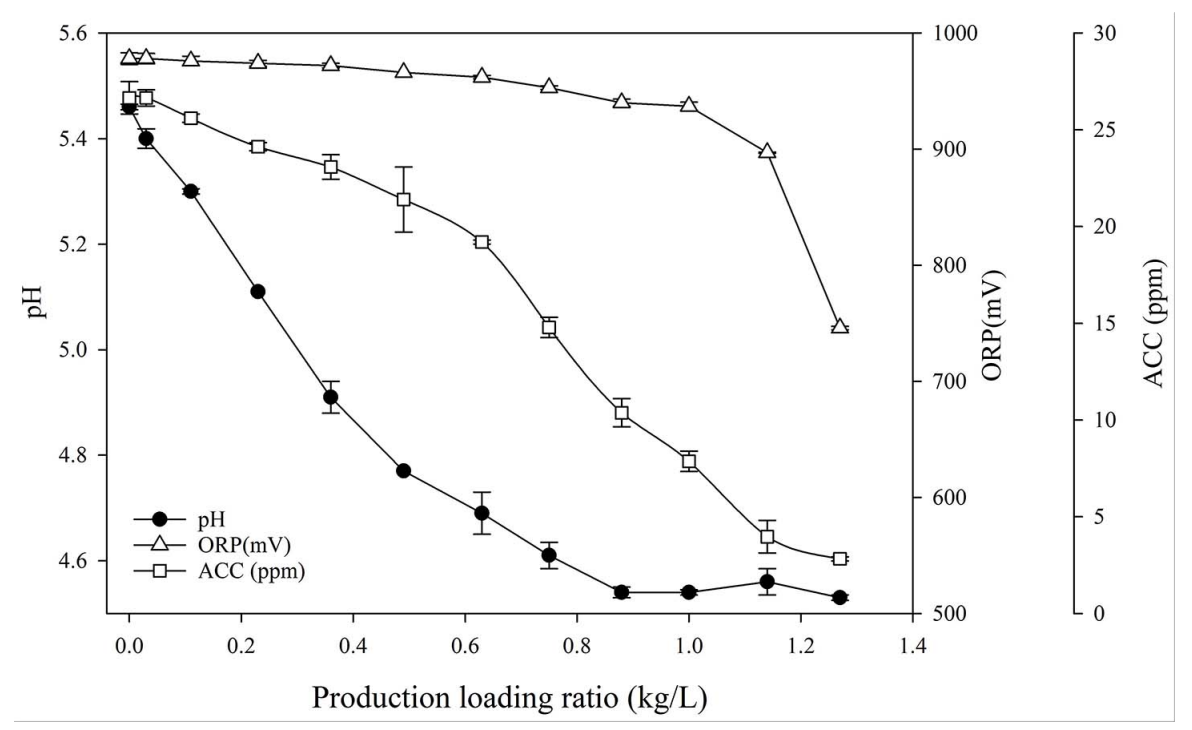

FIGURE 2 | Changes in the pH, ORP, and ACC of SAEW sampled after disinfection and washing fresh cabbages.

the $\mathrm{pH}$ was 5.0. Interestingly, when the cabbage/SAEW ratio was more than 0.3 , the $\mathrm{pH}$ of SAEW began to deviate from the effective disinfection range (between 5.0 and 6.0). This was a section where the reduction of the disinfection effect could be estimated. In addition, when the cabbage/SAEW ratio was 0.3, ORP maintained a level of approximately $980 \mathrm{mV}$ without significant differences, and ACC maintained a level of $23.6 \mathrm{ppm}$. ACC values had reduced by $3 \mathrm{ppm}$ from the initial value of $26.6 \mathrm{ppm}$. Thereafter, the $\mathrm{pH}$ value and ACC exhibited a tendency to decrease continuously. When the cabbage/SAEW ratio was 0.87 , the decrease in the $\mathrm{pH}$ value stopped at 4.54 . On the other hand, the ORP maintained a level of $940 \mathrm{mV}$ without significant differences until the cabbage/SAEW ratio was 1.0, and then rapidly changed to less than $900 \mathrm{mV}$ as the cabbage/SAEW ratio exceeded 1.0.

\section{Decay Kinetic Model of Virucidal Effects of Post-disinfection SAEW on HuNoV}

We investigated the dynamic changes in the virucidal efficacies of SAEW affected by cabbage disinfection and washing operating variables (cabbage-to-SAEW ratio). The cabbage loading ratio significantly affected the dynamic changes in the virucidal efficacies on HuNoV GI.6 and HuNoV GII.4 (Figures 3A,B). Increasing the amount of fresh cabbage washed in the same washing chamber with $100 \mathrm{~L}$ of SAEW resulted in a significant decrease in the reduction values of both $\mathrm{HuNoV}$ strains. Moreover, it led to a decrease in the $\mathrm{pH}$ value of the SAEW solution. The most interesting and novel findings in the present study are shown in Figures 3A,B. Although the initial disinfection and washing process showed excellent elimination of both HuNoV GI.6 and GII.4, with a reduction of approximately 5.02-5.32 log genomic copies, the obtained reduction values significantly and continuously diminished as the cabbage loading ratio increased. In particular, the reduction value of $\mathrm{HuNoV}$
GII.4 decreased to less than 3 log decrease as the cabbage/SAEW ratio exceeded 1.0, whereas the reduction value of HuNoV GI.6 maintained a 3 log decrease. Based on these data, we assumed that HuNoV GII.4 might be more resistant than HuNoV GI.6 to SAEW treatment. These data indicate that SAEW treatment loses efficiency as the cabbage concentration increased.

\section{Model Evaluation With Experimental Data}

The three model selection criteria used to investigate the correspondence between the obtained kinetic models are presented in Table 1. Generally, values close to zero for AIC, RMSE, and RSS indicate a better goodness-of-fit model. Thus, the lowest value obtained from the model selection criterion implies the preferred kinetic model. The decay kinetic model of virucidal effects on HuNoV by post-disinfection SAEW shows that the goodness-of-fit of the tested models are based on lower AIC values in both $\mathrm{HuNoV}$ strains. The RMSE values in the decay kinetics were 0.0217 (HuNoV GI.6) and 0.0452 (HuNoV GII.4). In addition, the RSS values from decay kinetics appeared to be appropriate for inactivation of both $\mathrm{HuNoV}$ strains.

\section{Pearson Correlation Coefficient Between Virucidal Effect and Physicochemical Parameters}

The Pearson correlation coefficients between the reduction value of HuNoV GI.6 and pH, ORP, and ACC were 0.945, 0.680, and 0.966 , respectively, and those between the reduction of HuNoV GII.4 and the above three factors were $0.835,0.789$, and 0.991, respectively (Table 2). Overall, $\mathrm{pH}$ and ACC were strongly correlated with a reduction in both $\mathrm{HuNoV}$ strain titers $(P<0.05)$. ACC showed the strongest correlation with the inactivation of HuNoV GI.6 $(R=0.966)$ and HuNoV GII.4 $(R=0.991)$. 

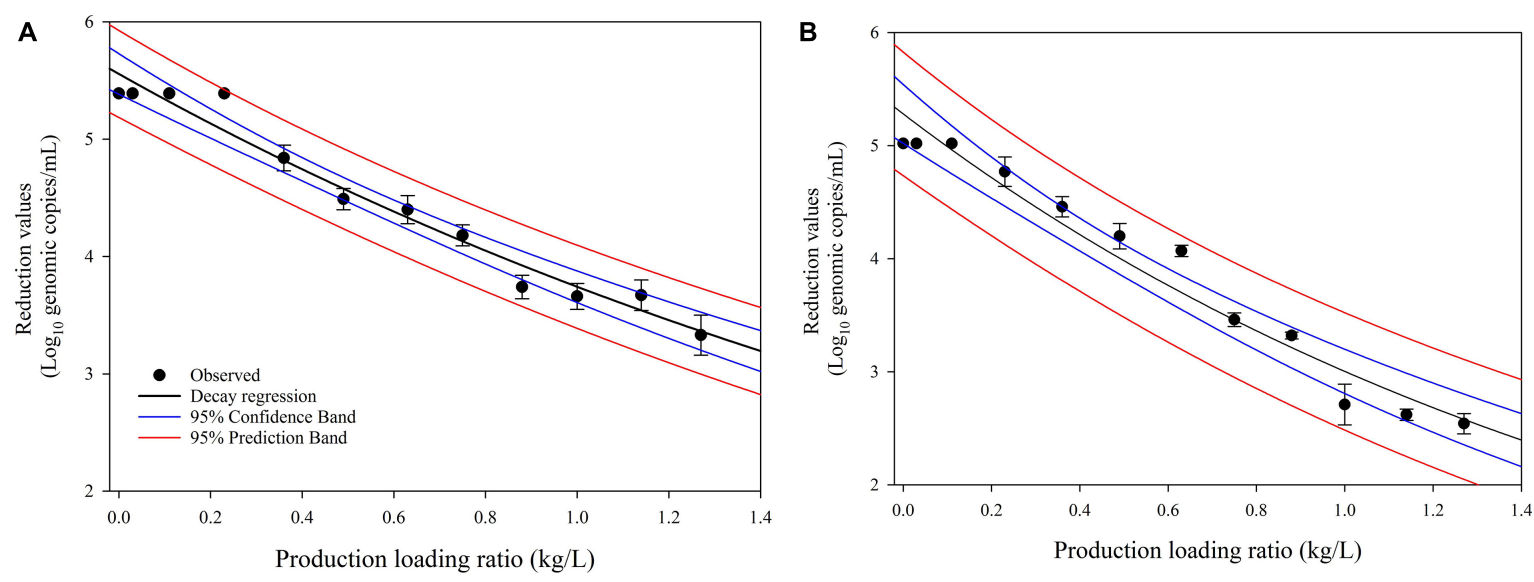

FIGURE 3 | Dynamic changes of the virucidal efficacies of (A) HuNoV Gl.6 and (B) HuNoV Gll.4 based on the cabbage loading ratio related to the total amount of SAEW.

TABLE 1 | Analysis of SAEW decay kinetic models in terms of reduction values of HuNoVs based on cabbage-to-SAEW ratio.

\begin{tabular}{|c|c|c|c|c|c|}
\hline \multicolumn{2}{|c|}{ Fitting model (decay kinetics) } & \multicolumn{4}{|c|}{ Parameter statistical distributions } \\
\hline & & ${ }^{1)} R^{2}$ & ${ }^{2)} \mathrm{AIC}$ & 3) RMSE & 4) RSS \\
\hline $\begin{array}{l}\text { HuNoV } \\
\text { Gl.6 }\end{array}$ & $\begin{array}{c}Y=5.5565 \times \\
\exp (-0.3952 \times X)\end{array}$ & 1.017 & 1.017 & 0.0217 & 0.2166 \\
\hline $\begin{array}{l}\text { HuNoV } \\
\text { Gll.4 }\end{array}$ & $\begin{array}{c}Y=5.2817 \times \\
\exp (-0.5646 \times X)\end{array}$ & 2.377 & 2.377 & 0.0465 & 0.4652 \\
\hline
\end{tabular}

${ }^{(1)} R^{2}$ is the coefficient of determination.

(2) $A / C$ is the Akaike information criterion.

${ }^{(3)}$ RMSE is the root-mean-square error.

${ }^{(4)} R S S$ is residual sum of squares.

TABLE 2 | Correlation coefficients between reduction value of HuNoVs and the values of $\mathrm{pH}, \mathrm{ORP}$, and ACC.

\begin{tabular}{lccc}
\hline $\begin{array}{l}\text { Reduction values }\left(\log _{10}\right. \\
\text { genomic copies) }\end{array}$ & \multicolumn{3}{c}{ Physicochemical properties } \\
\hline & pH & ORP (mV) & ACC (ppm) \\
\cline { 2 - 4 } & 0.945 & 0.680 & 0.966 \\
HuNoV Gl.6 & 0.835 & 0.789 & 0.991 \\
\hline
\end{tabular}

\section{DISCUSSION}

\section{Effect of MBS-PMA-INCI Pretreatment on RT-qPCR Assay}

Reverse transcription quantitative polymerase chain reaction has been used extensively to quantify and detect the viral particles owing to its sensitivity, specificity, and short assay time. Nevertheless, there is technical limit to the use of nucleic acid-based detection techniques for the assessment of viral particles after disinfection: their inability to distinguish infectious and non-infectious viruses in disinfected samples. MBS can be utilized to overcome this issue. The MBS technique for improving the sensitivity of virus concentration and detection has been verified in numerous studies (Tian et al., 2008; Morton et al., 2009; Pan et al., 2012). Moreover, Moore et al. (2016) reported that nucleic acid aptamers, as valuable ligands, can help discern the infectivity status of viral particles. In addition, there have been many new studies on differentiating intact viral particles using more advanced analysis techniques such as PMA or ethidium monoazide (EMA) pretreatments (Coudray-Meunier et al., 2013; Escudero-Abarca et al., 2014; Moreno et al., 2015; Randazzo et al., 2016). The intercalating dye eliminates false-positive results caused by the nonspecific binding to magnetic beads (Sánchez et al., 2012; Sangsanont et al., 2014). Therefore, the MBS/INCI/PMA/RT-qPCR assay used in this study is a reliable and suitable technique to capture and discrimination intact, damaged, and dead viral particles after SAEW disinfection.

\section{Changes in the Physicochemical Properties of SAEW}

For optimal disinfection, SAEW solution should be checked continuously, before and after the disinfection process, to prevent decrease of concentration below the disinfection limit of SAEW. However, there has been little research on the dynamics of the changes in physicochemical properties of SAEW during vegetable disinfection, although various studies have shown changes in the physicochemical properties (e.g., $\mathrm{pH}, \mathrm{ORP}$, and ACC) of EW in suspension (Tatsumi et al., 2007; Cui et al., 2009). Suboptimal disinfection conditions of EW due to changes in the $\mathrm{pH}, \mathrm{ORP}$, and ACC could reduce the microorganism inactivation (Park et al., 2004; Al-Haq et al., 2005). Len et al. (2002) reported that the major factor influencing the antimicrobial activity of acidic EW (AEW) is the fraction of chlorine compounds, $\mathrm{Cl}_{2}$ and $\mathrm{HOCl}$, and subsequent $\mathrm{HOCl}$ decomposition. Furthermore, bactericidal activities of chlorine compounds are $\mathrm{pH}$ dependent (Fabrizio and Cutter, 2004; Mahmoud et al., 2004). As a type of EW, the virucidal effect of SAEW also reacts sensitively to changes in $\mathrm{pH}$, ORP, and ACC. 
In our study, we found a strong correlation between virucidal activity and physicochemical parameters. These experimental data suggest that physicochemical factors of SAEW play a crucial role in the kinetic behavior of changes in SAEW during the disinfection process. ACC plays a more important role than $\mathrm{pH}$ and ORP in reducing foodborne pathogens (Hotta et al., 1994; Koseki et al., 2004; Kim et al., 2006). Hsu and Kao (2004) demonstrated that the primary reason for deterioration of EOW antimicrobial activity may be decomposition of chlorine compounds rather than changes in $\mathrm{pH}$ or ORP. Moreover, ACC in EOWs can be easily converted to the inactive form by changes in the EOW environment (Tamaki et al., 2014). Our findings also showed the strongest correlation coefficient between deterioration in virucidal activity of SAEW and the pattern of ACC decay.

\section{Decay of Virucidal Effects of Post-disinfection SAEW on HuNoV}

Several studies have investigated decay kinetic models of chlorine for public water distribution systems (Hua et al., 1999; Le Dantec et al., 2002) and activated sludge (Caravelli et al., 2003). Li et al. (2013) reported chlorine decay kinetic models for AEW during storage against foodborne pathogens such as Vibrio parahaemolyticus and Listeria monocytogenes in suspension. However, to date, there have been few studies regarding the decay kinetics of the virucidal effects of SAEW during disinfection and wash treatment of fresh cabbage. Furthermore, most studies on the kinetics of inactivation based on chlorine conditions were dependent on exposure time (Le Dantec et al., 2002; Caravelli et al., 2003). However, the decay of SAEW during the disinfection maintenance stage was not sufficient during the actual disinfection process. In the present study, we determined the virucidal decay behavior based on the change in the ratio of cabbage load to the total SAEW volume. In particular, this study was performed at a pilot scale to evaluate the real washing and disinfection processes. Our results indicated that increasing the amount of fresh cabbage for washing in fixed $100 \mathrm{~L}$ of SAEW resulted in a significant decrease in the reduction of both HuNoV GI.6 and GII.4. This demonstrates the continuous accumulation of organic substances from washed cabbage in the SAEW, leading to SAEW deterioration. Our results are consistent with those of Tamaki et al. (2014). The effectiveness of the various types of EOWs could be considered as short term because highly reactive oxidative moieties in EOWs would react with any organic compound present during the cabbage washing process. Furthermore, ACC in EOWs can be quickly altered to the inactive form. Therefore, our results regarding decay kinetic models of SAEW for washing and disinfection systems provide experimental data to effectively sterilize and wash cabbage using SAEW. The developed exponential decay model for HuNoVs reduction by treating sampled SAEW after the washing process of fresh cabbage gave statistically acceptable fits. In the kinetic models, the model selection criteria, including RSS, AIC, and RMSE based on goodness of fit, indicated an acceptable goodness of fit of both the HuNoV GI.6 and HuNoV GII.4.

The organic load from wash water is a crucial parameter that affects the inactivation activities of disinfectant washing treatment. Like other oxidative disinfectants, fractions of chlorine compounds are highly reactive to organic materials and could be rapidly deteriorated by organic matter in the disinfection agent (Gil et al., 2009). In particular, Luo et al. (2012) demonstrated that a significant number of organic substances, including exudate from surfaces of vegetable debris, soil, and various material particles, are transferred into the disinfectant solution. This causes rapid decay of disinfectant quality, manifested by changes in $\mathrm{pH}, \mathrm{ORP}$, and ACC. Luo et al. (2012) reported that the washing process achieved lower bacterial reduction with larger produce-towash water ratio. According to Pirovani et al. (2001), the produce-to-water ratio that would allow efficient microbial inactivation is not clear, and the microbial reduction achieved depends on the operating conditions (e.g., water-to-produce ratio, disinfectant condition, exposure time, and temperature) and the type of vegetables. Therefore, several studies have evaluated operational variables such as water-to-produce ratio and washing time. Pirovani et al. $(2001,2004)$ reported that a higher produce-to-water ratio can significantly reduce microbial inactivation. Similarly, in our study, the reduction of both $\mathrm{HuNoVs}$ was significantly and continuously diminished as the cabbage loading ratio increased. Our results indicated that inactivation efficacy of post-disinfection SAEW on both HuNoVs strains was affected by the cabbage-to-SAEW ratio. Furthermore, the deterioration of inactivation levels in postdisinfection SAEW used in this study was similar to what was demonstrated in the decay pattern of post-disinfectant water samples obtained from a fresh-cut lettuce processing plant (Nou et al., 2011).

\section{Virucidal Effects of EW}

Although it is known that $\mathrm{pH}$, chlorine compounds, ORP, or combinations of these variables have a significant role in the antimicrobial activity of SAEW, there is no evidence that they are associated with inactivation of foodborne or waterborne viruses. Hati et al. (2012) reported that the antimicrobial mechanisms of AEW could be primarily attributed to three variables: availability of chlorine compounds, ORP, and $\mathrm{pH}$. The virucidal effect of AEW has been evaluated for herpes simplex viruses, hepatitis B virus, human immunodeficiency virus, and enteric viruses (Tanaka et al., 1999; Morita et al., 2000; Tagawa et al., 2000; Park et al., 2007). Moreover, Moorman et al. (2017) reported that neutral electrolyzed water (NEW) at $250 \mathrm{ppm}$ had virucidal effects on HuNoV GII.4 in suspension and on stainless steel surfaces. Furthermore, NEW showed promising results as a virucidal treatment when applied on food contact surfaces. Tamaki et al. (2014) reported that both $\mathrm{H} 5 \mathrm{~N} 1$ and $\mathrm{H} 9 \mathrm{~N} 2$ viruses were inactivated by $5 \log 60 \mathrm{~s}$ after the viruses were treated with AEW, in which the ACC ranged from 0 to $72 \mathrm{ppm}$. Interestingly, Tamaki et al. (2014) demonstrated that AEW influences viral inactivation effectiveness in an ACC-independent 
manner and for a relatively long period. However, in our study, it is noteworthy that in both HuNoVs strains, inactivation efficacy of post-disinfection SAEW is ACC dependent. The AEW produced in the anode chamber of an EW generator generally presents high ORP and low $\mathrm{pH}$ values, unlike SAEW. Interestingly, it was demonstrated that the $\mathrm{pH}$ value of AEW was inversely proportional to the ORP value (Al-Haq et al., 2002), and decreasing the $\mathrm{pH}$ increased the virucidal potential of AEW, even if chlorine compounds $\left(\mathrm{HOCl}, \mathrm{Cl}_{2}\right.$, and $\left.\mathrm{ClO}^{-}\right)$were kept constant (Park et al., 2004). However, the $\mathrm{pH}$ value of SAEW was proportional to the ACC and ORP values, respectively, in our results. This was unexpected because both EW and SAEW are substances with similar chemical properties. This discrepancy may be attributed to the organic substances from the washed cabbages. Furthermore, differences in various food matrices among fresh vegetables could lead to different results for the virucidal effects of SAEW.

In this study, our experimental data demonstrated that physicochemical parameters of SAEW play a key role in describing the kinetics of changes in SAEW properties during the cabbage disinfection process. The three selection criteria, AIC, RMSE, and RSS, used to determine the correspondence between the obtained kinetic models were close to zero, indicating statistically acceptable fits. Furthermore, our findings showed a strong correlation coefficient with the deterioration in the virucidal effect of SAEW and the changes in $\mathrm{pH}, \mathrm{ACC}$, and ORP. Therefore, for SAEW to be used efficiently in the pre-treatment

\section{REFERENCES}

Al-Haq, M. I., Seo, Y., Oshita, S., and Kawagoe, Y. (2002). Disinfection effects of electrolyzed oxidizing water on suppressing fruit rot of pear caused by Botryosphaeria berengeriana. Food Res. Int. 35, 657-664. doi: 10.1016/s09639969(01)00169-7

Al-Haq, M. I., Sugiyama, J., and Isobe, S. (2005). Applications of electrolyzed water in agriculture and food industries. Food Sci. Technol. Res. 11, 135-150. doi: $10.3136 /$ fstr.11.135

Cap, M., Vaudagna, S., Mozgovoj, M., Soteras, T., Sucari, A., Signorini, M., et al. (2019). Inactivation of shiga toxin-producing Escherichia coli in fresh beef by electrolytically-generated hypochlorous acid, peroxyacetic acid, lactic acid and caprylic acid. Meat Sci. 157:107886. doi: 10.1016/j.meatsci.2019. 107886

Caravelli, A., Contreras, E. M., Giannuzzi, L., and Zaritzky, N. (2003). Modeling of chlorine effect on floc forming and filamentous microorganisms of activated sludges. Water Res. 37, 2097-2105. doi: 10.1016/s0043-1354(02) 00601-2

Coudray-Meunier, C., Fraisse, A., Martin-Latil, S., Guillier, L., and Perelle, S. (2013). Discrimination of infectious hepatitis A virus and rotavirus by combining dyes and surfactants with RT-qPCR. BMC Microbiol. 13:216. doi: 10.1186/1471-2180-13-216

Cui, X. D., Shang, Y. C., Shi, Z., Xin, H., and Cao, W. (2009). Physicochemical properties and bactericidal efficiency of neutral and acidic electrolyzed water under different storage conditions. J. Food Eng. 91, 582-586. doi: 10.1016/j. jfoodeng.2008.10.006

Escudero-Abarca, B. I., Rawsthorne, H., Goulter, R. M., Suh, S. H., and Jaykus, L. A. (2014). Molecular methods used to estimate thermal inactivation of a prototype human norovirus: more heat resistant than previously believed? Food Microbiol. 41, 91-95. doi: 10.1016/j.fm.2014.01.009

Fabrizio, K. A., and Cutter, C. N. (2004). Comparison of electrolyzed water with other antimicrobial interventions to reduce pathogens on fresh pork. Meat Sci. 68, 463-468. doi: 10.1016/j.meatsci.2004.04.013 for washing and disinfection of fresh vegetables, it is necessary to optimize the produce-to-SAEW ratio as operating variables in future studies.

\section{DATA AVAILABILITY STATEMENT}

The original contributions presented in the study are included in the article/supplementary material, further inquiries can be directed to the corresponding author.

\section{AUTHOR CONTRIBUTIONS}

MK and BP performed most of the experiments, analyzed the data, and wrote the first draft of the manuscript. J-HH was responsible for the experimental design, data coordination, analysis and interpretation, and writing, revision, and finalization of the manuscript. All authors have read and approved the final manuscript.

\section{FUNDING}

This research was supported by grants from the World Institute of Kimchi (KE2002-2) and funded by the Ministry of Science and ICT, South Korea.

Fenner, D. C., Bürge, B., Kayser, H. P., and Wittenbrink, M. M. (2006). The anti-microbial activity of electrolysed oxidizing water against microorganisms relevant in veterinary medicine. J. Vet. Med. B 53, 133-137. doi: 10.1111/j.14390450.2006.00921.x

Gentry, J. B., Vinje, J., and Lipp, E. K. (2009). A rapid and efficient method for quantitation of genogroups I and II norovirus from oysters and application in other complex environmental samples. J. Virol. Methods 156, 59-65. doi: 10.1016/j.jviromet.2008.11.001

Gil, M. I., Selma, M. V., Lopez-Galvez, F., and Allende, A. (2009). Fresh-cut product sanitation and wash water disinfection: problems and solutions. Int. J. Food Microbiol. 134, 37-45. doi: 10.1016/j.ijfoodmicro.2009. 05.021

Ha, J. H., Choi, C., Lee, H. J., Ju, H. J., Lee, J. H., and Ha, S. D. (2016). Efficacy of chemical disinfectant compounds against human norovirus. Food Control 59, 524-529. doi: 10.1016/j.foodcont.2015.04.040

Hao, J. X., Liu, H. J., Liu, R., Dalai, W. Y., Zhao, R. P., Chen, T. P., et al. (2011). Efficacy of slightly acidic electrolyzed water (SAEW) for reducing microbial contamination on fresh-cut cilantro. J. Food Saf. 31, 28-34. doi: 10.1111/j.17454565.2010.00261.X

Hao, X., Cao, W., Li, B., Zhang, Q., Wang, C., and Ge, L. (2014). Slightly acidic electrolyzed water for reducing airborne microorganisms in a layer breeding house. J. Air Waste Manag. Assoc. 64, 494-500. doi: 10.1080/10962247.2013. 870940

Hati, S., Mandal, M., Minz, P. S., Vij, S., Khetra, Y., Singh, B. P., et al. (2012). Electrolyzed oxidized water (EOW): Non-thermal approach for decontamination of food borne microorganisms in food industry. Food Nut. Sci. 3, 760-768. doi: 10.4236/fns.2012.36102

Hotta, K., Kawaguchi, K., Saitoh, F., Saitoh, N., Suzuki, K., Ochi, K., et al. (1994). Antimicrobial activity of electrolyzed $\mathrm{NaCl}$ solutions: effect on the growth of Streptomyces spp. Actinomycetologica 8, 51-56. doi: 10.3209/saj.8_51

Hricova, D., Stephan, R., and Zweifel, C. (2008). Electrolyzed water and its application in the food industry. J. Food Prot. 71, 1934-1947. doi: 10.4315/ 0362-028x-71.9.1934 
Hsu, S. Y., and Kao, H. Y. (2004). Effects of storage conditions on chemical and physical properties of electrolyzed oxidizing water. J. Food Eng. 65, 465-471. doi: 10.1016/j.jfoodeng.2004.02.009

Hua, F., West, J. R., Barker, R. A., and Forster, C. F. (1999). Modelling of chlorine decay in municipal water supplies. Water Res. 33, 2735-2746. doi: 10.1016/ s0043-1354(98)00519-3

Issa-Zacharia, A., Kamitani, Y., Miwa, N., Muhimbula, H., and Iwasaki, K. (2011). Application of slightly acidic electrolyzed water as a potential nonthermal food sanitizer for decontamination of fresh ready-to-eat vegetables and sprouts. Food Control 22, 601-607. doi: 10.1016/j.foodcont.2010. 10.011

Kim, W.-T., Lim, Y.-S., Hin, I.-S., Park, H., Chung, D., and Suzuki, T. (2006). Use of electrolyzed water ice for preserving freshness of pacific saury (Cololabis saira). J. Food Prot. 69, 2199-2204. doi: 10.4315/0362-028x-69.9. 2199

Koide, S., Takeda, J.-I., Shi, J., Shono, H., and Atungulu, G. G. (2009). Disinfection efficacy of slightly acidic electrolyzed water on fresh cut cabbage. Food Control 20, 294-297. doi: 10.1016/j.foodcont.2008.05.019

Koseki, S., Isobe, S., and Itoh, K. (2004). Efficacy of acidic electrolyzed water ice for pathogen control on lettuce. J. Food Prot. 67, 2544-2549. doi: 10.4315/0362028x-67.11.2544

Le Dantec, C., Duguet, C., Montiel, A., Dumoutier, N., Dubrou, S., and Vincent, V. (2002). Chlorine disinfection of atypical Mycobacteria isolated from a water distribution system. Appl. Environ. Microbiol. 60, 1025-1032. doi: 10.1128/aem. 68.3.1025-1032.2002

Lee, H.-W., Lee, H.-M., Yoon, S.-R., Kim, S. H., and Ha, J.-H. (2018). Pretreatment with propidium monoazide/sodium lauroyl sarcosinate improves discrimination of infectious waterborne virus by RT-qPCR combined with magnetic separation. Environ. Pollut. 233, 306-314. doi: 10.1016/j.envpol.2017. 10.081

Len, S. V., Hung, Y. C., Chung, D., Anderson, J. L., Erickson, M. C., and Morita, K. (2002). Effects of strorage condition and $\mathrm{pH}$ on chlorine loss in electrolysed oxidizing (EO) water. J. Agric. Food Chem. 50, 209-212. doi: 10.1021/jf010 $822 \mathrm{v}$

Li, X., Jiang, D., and Zhang, Y. (2013). The self-decay characteristics of chlorine dioxide in water. Adv. Mat. Res. 610-613, 296-299. doi: 10.4028/www.scientific. net/amr.610-613.296

Luo, Y., Nou, X., Millner, P., Zhou, B., Shen, C., Yang, Y., et al. (2012). A pilot plant scale evaluation of a new process aid for enhancing chlorine efficacy against pathogen survival and cross-contamination during produce wash. Int. J. Food Microbiol. 158, 133-139. doi: 10.1016/j.ijfoodmicro.2012. 07.008

Mahmoud, B. S., Yamazaki, K., Miyashita, S., Il-Shik, C., Dong-Suk, C., and Suzuki, T. (2004). Decontamination effect of electrolyzed $\mathrm{NaCl}$ solutions on carp. Lett. Appl. Microbiol. 39, 169-173. doi: 10.1111/j.1472-765x.2004. 01557.x

Moore, M. D., Bobay, B. G., Mertens, B., and Jaykus, L. (2016). Human norovirus aptamer exhibits high degree of target conformation-dependent binding similar to that of receptors and discriminates particle functionality. mSphere 1:e0029816. doi: 10.1128/mSphere.00298-16.Editor

Moorman, E., Montazeri, N., and Jaykus, L. A. (2017). Efficacy of neutral electrolyzed water for inactivation of human norovirus. Appl. Environ. Microbiol. 83:e00653-17. doi: 10.1128/AEM.00653-17

Moreno, L., Aznar, R., and Sánchez, G. (2015). Application of viability PCR to discriminate the infectivity of hepatitis A virus in food samples. Int. J. Food Microbiol. 201, 1-6. doi: 10.1016/j.ijfoodmicro.2015. 02.012

Morita, C., Sano, K., Morimatsu, S., Kiura, H., Goto, T., Kohno, T., et al. (2000). Disinfection potential of electrolyzed solutions containing sodium chloride at low concentrations. J. Virol. Methods 85, 163-174. doi: 10.1016/s0166-0934(99) 00165-2

Morton, V., Jean, J., Farber, J., and Mattison, K. (2009). Detection of noroviruses in ready-to-eat foods by using carbohydrate-coated magnetic beads. Appl. Environ. Microbiol. 75, 4641-4643. doi: 10.1128/aem. 00202-09

Nou, X., Luo, Y., Hollar, L., Yang, Y., Feng, H., Millner, P., et al. (2011). Chlorine stabilizer T-128 enhances efficacy of chlorine against cross-contamination by
E. coli $\mathrm{O} 157: \mathrm{H7}$ and Salmonella in fresh-cut lettuce processing. J. Food Sci. 76, M218-M224. doi: 10.1111/j.1750-3841.2011.02046.x

Pan, L., Zhang, Q., Li, X., and Tian, P. (2012). Detection of human norovirus in cherry tomatoes, blueberries and vegetable salad by using a receptor-binding capture and magnetic sequestration (RBCMS) method. Food Microbiol. 30, 420-426. doi: 10.1016/j.fm.2011.12.026

Park, G. W., Boston, D. M., Kase, J. A., Sampson, M. N., and Sobsey, M. D. (2007). Evaluation of liquid- and fog-based application of sterilox hypochlorous acid solution for surface inactivation of human norovirus. Appl. Environ. Microbiol. 73, 4463-4468. doi: 10.1128/aem.02839-06

Park, H., Hung, Y.-C., and Chung, D. (2004). Effects of chlorine and pH on efficacy of electrolyzed water for inactivating Escherichia coli O157:H7 and Listeria monocytogenes. Int. J. Food Microbiol. 91, 13-18. doi: 10.1016/s0168-1605(03) 00334-9

Pirovani, M., Guemes, D., and Piagnetini, A. (2001). Predictive models for available chlorine depletion and total microbial count reduction during washing of fresh-cut spinach. J. Food Sci. 66, 860-864. doi: 10.1111/j.1365-2621.2001.tb 15187.x

Pirovani, M., Piagentini, A., Guemes, D., and Arkwright, S. (2004). Reduction of chlorine concentration and microbial load during washing-disinfection of shredded lettuce. Int. J. Food Sci. Tech. 39, 341-347. doi: 10.1111/j.1365-2621. 2004.00791.x

Rahman, S. M. E., Ding, T., and Oh, D.-H. (2010). Inactivation effect of newly developed low concentration electrolyzed water and other sanitizers against microorganisms on spinach. Food Control 21, 1383-1387. doi: 10.1016/j. foodcont.2010.03.011

Rahman, S. M. E., Wang, J., and Oh, D.-H. (2013). Synergistic effect of low concentration electrolyzed water and calcium lactate to ensure microbial safety, shelf life and sensory quality of fresh pork. Food Control 30, 176-183. doi: 10.1016/j.foodcont.2012.06.041

Randazzo, W., López-Gálvez, F., Allende, A., Aznar, R., and Sánchez, G. (2016). Evaluation of viability PCR performance for assessing norovirus infectivity in fresh-cut vegetables and irrigation water. Int. J. Food Microbiol. 229, 1-6. doi: 10.1016/j.ijfoodmicro.2016.04.010

Ren, T., and Su, Y. C. (2006). Effects of electrolyzed oxidizing water treatment on reducing Vibrio parahaemolyticus and Vibrio vulnificus in raw oysters. J. Food Prot. 69, 1829-1834. doi: 10.4315/0362-028X-69.8. 1829

Sánchez, G., Elizaquível, P., and Aznar, R. (2012). Discrimination of infectious hepatitis A viruses by propidium monoazide real-time RT-PCR. Food Environ. Virol. 4, 21-25. doi: 10.1007/s12560-011-9074-5

Sangsanont, J., Katayama, H., Kurisu, H., and Furumai, H. (2014). Capsiddamaging effects of UV irradiation as measured by quantitative PCR coupled with ethidium monoazide treatment. Food Environ. Virol. 6, 269-275. doi: 10.1007/s12560-014-9162-4

Schwarz, K. R., Sidhu, J. P. S., Toze, S., Li, Y., Lee, E., Gruchlik, Y., et al. (2019). Decay rates of Escherichia coli, Enterococcus spp., F-specific bacteriophage MS2, somatic coliphage and human adenovirus in facultative pond sludge. Water Res. 154, 62-71. doi: 10.1016/j.watres.2019. 01.027

Suzuki, K., Nakamura, T., Doi, T., Kokubo, S., and Tomita, M. (2005). The disinfectant effect of slightly acidic electrolyzed water prepared with hydrochloric acid as a raw material for lettuce. J. Antibacterial Antifungal Agents 33, 589-597.

Tagawa, M., Yamaguchi, T., Yokosuka, O., Matsutani, S., Maeda, T., and Saisho, H. (2000). Inactivation of a hepadnavirus by electrolyzed acid water. J. Antimicrob. Chemother. 46, 363-368. doi: 10.1093/jac/46.3.363

Tamaki, S., Bui, V. N., Ngo, L. H., Ogawa, H., and Imai, K. (2014). Virucidal effect of acidic electrolyzed water and neutral electrolyzed water on avian influenza viruses. Arch. Virol. 159, 405-412. doi: 10.1007/s00705-013$1840-2$

Tanaka, N., Fujisawa, T., Daimon, T., Fujiwara, K., Tanaka, N., Yamamoto, M., et al. (1999). The effect of electrolyzed strong acid aqueous solution on hemodialysis equipment. Artif. Organ 23, 1055-1062. doi: 10.1046/j.1525-1594.1999. 06224.x

Tatsumi, Y., Umimoto, K., Kumayama, Y., and Jokei, K. (2007). Effect of longterm storage on bactericidal activity of strong acidic electrolyzed water. World 
Congr. Med. Phys. Biomed. Eng. 14, 3733-3736. doi: 10.1007/978-3-540-368410_945

Tian, M., Jin, M., Xiem, H., Duan, Z., Jiang, X., and Fang, Z. (2008). Outbreak studies of a GII-3 and a GII-4 norovirus revealed an association between HBGA phenotypes and viral infection. J. Med. Virol. 80, 1296-1301. doi: 10. 1002/jmv. 21200

Wang, J. J., Zhang, Z. H., Li, J. B., Lin, T., Pan, Y. J., and Zhao, Y. (2014). Modeling Vibrio parahaemolyticus inactivation by acidic electrolyzed water on cooked shrimp using response surface methodology. Food Control 36, 273-279. doi: 10.1016/j.foodcont.2013.08.031
Conflict of Interest: The authors declare that the research was conducted in the absence of any commercial or financial relationships that could be construed as a potential conflict of interest.

Copyright (c) 2021 Kang, Park and Ha. This is an open-access article distributed under the terms of the Creative Commons Attribution License (CC BY). The use, distribution or reproduction in other forums is permitted, provided the original author(s) and the copyright owner(s) are credited and that the original publication in this journal is cited, in accordance with accepted academic practice. No use, distribution or reproduction is permitted which does not comply with these terms. 